\title{
An online emergency medical management information system using mobile computing
}

\author{
Sarandis Mitropoulos \\ Ionian University, Lefkada, Greece, and \\ Christos Mitsis, Petros Valacheas and Christos Douligeris \\ University of Piraeus, Piraeus, Greece
}

Received 27 March 2021

Revised 26 April 2021

Accepted 11 May 2021

\begin{abstract}
Purpose - The purpose of this paper is to investigate the way technology affects the provision of prehospital emergency care, upgrading the quality of services offered and significantly reducing the risk of premature termination of the patients.

Design/methodology/approach - The paper presents the development of the eEKAB, a pilot emergency medical information system that simulates the main services offered by the Greek National Instant Aid Centre (EKAB). The eEKAB was developed on an agile system methodology. From a technical perspective, the features and the technology were mainly chosen to provide reliable and user-friendly interfaces that will attract many users. eEKAB is based on three important pillars for offering health care to the patients: the "On-time Incident Reporting", the "On-time Arrival at the Incident" and "Transfer to the Health Center". According to the literature review, the emergency medical services (EMS) systems that combine all the features are very few. Findings - It reduces the total time of the EMS procedures and it allows for an easier management of EMS, by providing a better allocation of human resources and a better geographical distribution of ambulances. The evaluation displayed that it is a very helpful application for the ambulance drivers as it reduces the ambulance response time to arrive in the patient's location and contributes significantly to the general performance of the prehospital medical care system. Also, the survey verified the importance of implementing eEKAB on a larger scale beyond the pilot usage. It is worth mentioning that the younger ambulance drivers had a more positive view for the purpose of the application.

Research limitations/implications - The paper clearly identifies implications for further research. Regarding interoperability, the mobile app cooperates with the Operational Center of EKAB, while further collaboration could be achieved with other operational ambulance handling center, mainly, of the private sector. The system can evolve to include better communications among the EKAB departments. Particularly, the ambulance crew as well as the doctors should be informed with more incident features such as the emergency signal so that they know whether to open the siren, the patient's name, etc. The authors are currently working on implementing some features to provide effective medical health services to the patient in the ambulance.

Practical implications - eEKAB will have very significant implications in case of its enforcement, such as the reduction of the total time of EMS procedures with a corresponding reduction of the operating costs of an accident management system and an ambulance fleet handling system while in parallel informing in time the doctors/clinics. It will provide better distribution of ambulances as well as of total human resources. It will greatly assist ambulance drivers, while reducing ambulance response time to reach the patient's location. In other words, the authors will have a better performance of the whole prehospital care system.

Social implications - Providing emergency care before the hospital is of great importance for upgrading the quality of health services provided at the accident site, thus significantly reducing the risk of premature death of patients. This in itself has a significant social implication.
\end{abstract}

(C) Sarandis Mitropoulos, Christos Mitsis, Petros Valacheas and Christos Douligeris. Published in Applied Computing and Informatics. Published by Emerald Publishing Limited. This article is published under the Creative Commons Attribution (CC BY 4.0) licence. Anyone may reproduce, distribute, translate and create derivative works of this article (for both commercial and non-commercial purposes), subject to full attribution to the original publication and authors. The full terms of this licence may be seen at http:// creativecommons.org/licences/by/4.0/legalcode

Authors would like to thank Mr. A. Veletsos for his help in editing.

computing for emergencies

(1) 
Originality/value - The paper demonstrates a solid understanding in the field of the EMS systems and the corresponding medical services offered. It proposes the development of an effective, feasible and innovative EMS information system that will improve the existing emergency health care system in Greece (EKAB). An in depth literature review and presentation of the adopted new technologies and the respective architecture take place. An evaluation and statistical validation were conducted for proving the high applicability of eEKAB in case of real-life running.

Keywords Emergency medical service, Mobile apps, GIS, Management information system

Paper type Research paper

\section{Introduction}

The medical sector has entrusted many of its crucial processes and services to information and communication technologies, thus offering patients more efficient quality services [1]. The rapid increase in the ubiquity and acceptance combined with a significant cost reduction of the telecommunication services has also played a major role in optimizing health services. Nowadays, through a mobile phone, one can access the Internet, communicate with anyone, always know one's accurate location and choose the best route to a desired destination [1]. The development of systems that take advantage of these innovations is of paramount importance in the emergency medical services (EMS) sector and in the prehospital emergency health care response [2].

EMS can be defined as "an integrated system that provides staff, facilities and equipment arrangements for the effective, coordinated and timely provision of health and safety services to victims of a sudden illness or injury. The purpose of this system is to provide timely and lifethreatening care to victims of sudden injuries or emergencies to avoid mortality or long-term morbidity" [2]. The EMS operation can be divided into four main components: first-aid access, community care, on-road care and care upon arrival at the health center for the patient's treatment [2].

Though EMS operations vary greatly, depending on geographic location, topography, available resources and the laws of the country, yet a set of common events and related objectives in all the EMS are visible [3, 4] at https://bit.ly/2R5b2IM.

The efforts to modernize EMS vary depending on the sociocultural and economic factors of a country $[1,5]$. An information system that will integrate these steps promptly and effectively is of paramount importance [6].

The present study investigates how technology affects the provision of emergency care before the hospital and upgrades the quality of services provided to significantly reduce poor prognosis for patients. An information system/mobile app (eEKAB) compatible with the Greek National Instant Aid Centre (EKAB) to provide a variety of prehospital services to enhance the performance of EMS is presented. The mobile phones maintained in ambulances and kept by doctors will be connected to a central server in the EKAB control center that conveys an incident immediately to the nearest ambulances/doctors, and as a result, EMS will be able to handle incidents very quickly. The eEKAB contains a database connected to mobile receivers located in the ambulances or held by doctors and notifies the service provider closest to the incident by employing a mapping application.

\section{Literature review on models and systems}

Two different EMS models are used in Europe and in the USA, following the philosophy of the Franco-German and of the Anglo-American models, respectively. These models differ on the philosophy they follow for the patient's admission and transition at the health center.

According to the Franco-German model, based on "stay-and-stabilize" approach, rescuers at the site of incident with an emphasis on providing first aid stabilize the patient's health before transferring the subject to a health center for further care. This model is mainly applied 
by doctors in ambulances, performing crucial medical assessments and treat the patients at the incident scene. In this model, most of the patients are treated locally rather than being transferred to a hospital facility for treatment. On recommendation of the doctors in the ambulance, the patients requiring further treatment are transported directly to the wards, bypassing the emergency department. This model is widespread in Europe [1, 2, 4, 7].

The Anglo-American model is based on the "scoop-and-run" philosophy. Its purpose is to transfer patients as quickly as possible to the health center with less prehospital medical care. In countries following this model, the prehospital medical service usually cooperates more closely with the police and fire departments instead of the health services and the hospitals. Almost all patients in this model are transferred to specialized emergency centers instead of hospital wards. Some of the countries that follow this model are the USA, Canada, New Zealand and Australia [1, 2, 4, 7].

Various surveys have tried to compare these two models in terms of cost-effectiveness and results, but ultimately it seems that these two models cannot be fully and fairly compared because they work in different contexts and meet different types of requirements [2]. Additionally, the lack of uniform standards makes the comparison impossible.

Several mobile applications have been developed to enhance the EMS efficiency $[8,9]$. These systems use of variety of technologies, including computer-aided dispatch (CAD), mobile data terminals (MDTs) and geographical information systems (GIS).

The CAD technology is a combination of hardware and software that provides data input, suggests resources/vehicles/means of transport, alerts, detects and monitors the course of these resources before, during and after the alarm, and maintains an alarm file for deeper analysis [10]. In the most modern $\mathrm{CAD}$ systems, the call center operators receive emergency calls through systems such as the E911, which is used in the USA [10,11]. This system is connected to a computer and has automatic number recognition and location detection. It automatically enters the caller's phone number and address into the CAD system, reducing the required time for processing the help request. All this incident information is extracted and entered in the $\mathrm{CAD}$. When the CAD system has enough information to be able to propose a response template, it gives this proposal to the operator for approval. There is no need for the operator to consult maps, check the availability of units, determine the appropriate response, notify the unit wirelessly and announce the incident. If the operator agrees with the $\mathrm{CAD}$ proposal, then at a button push, the alarm is forwarded to the appropriate unit. In most systems, this can be achieved within 30 to 45 seconds [12-14]. Modern CAD systems are extremely complex. They are not only limited to alarm processing, but they also perform many other functionalities. CAD systems can provide the operator with a medical history of patients who can then transfer it to the unit crews for more effective incident management. They can also send the shortest route maps to the crews, record all the information of the incident evolution in a file, create an incident history and many other services [12-14].

GIS have been used to optimize prehospital medical care systems by providing important information to EMS. Information of historical incidents is analyzed to determine staffing and resource needs as well as the optimal location of an ambulance using GIS data. GIS also provide the operators of the dispatch center with a complete picture of ambulances and other units, as well as their ability to respond to incident cases [15]. GIS have been incorporated with global positioning systems (GPS) to provide an extremely important advantage to CAD functions, i.e. the ability to locate ambulances as well as to ensure that the most appropriate and the nearest available ambulance is sent to the incident.

MDTs are commonly placed inside the vehicles and receive messages from a control center presenting all the necessary information on their screen. They replace and sometimes work in parallel to the traditional radio communications between the driver and the operator at the control center. MDTs can automatically send the vehicle location, the passengers' number, the engine condition and other information [16]. 
EMS have a variety of features and characteristics [17]. For example, TrackerAssist is based on wireless communications and GPS technologies, providing valuable EMS services which include personal tracking, emergency notifications and incident reporting. More specifically, an emergency text message or email with a map of the patient's location is transmitted to notify all the preselected contacts when an emergency arises, allowing fast patient treatment.

ManDown is another mobile medical alert application, which takes advantage of motion sensing technologies that allow the identification of a lack of movement of an observed patient. If the patient has not moved for more than a fixed interval (e.g. 1 or 2 hours), then an alarm module and the GPS safety tracker are activated to notify the emergency contacts using the GPS location functionalities. Both TrackerAssist and ManDown are used for fast and accurate medical emergency reporting [17].

The Medical Priority Dispatch System (MPDS) [18] sends the most appropriate resources at the right time. Deployment plans place resources around the region in such a way that minimize response times. By sending a unit to the closest and highest priority call, the MPDS helps the dispatchers to properly distribute the available resources to achieve the best possible results.

STREMS uses wearable sensing technology to gather the important medical data of the patient and automatically stream them to the hospital prior to the ambulance arrival. It aims to minimize the handoff time between prehospital and in-hospital medical care. The ambulance crew can directly communicate with the hospital medical group to receive any guidelines via video. STREMS bridges the gap between the offered emergency health care services when an incident occurs and the medical services offered in the hospital [19].

Nowadays, the electronic Patient Care Reporting (ePCR) products play a crucial role in saving time and offering effective EMS services to patients, as well as allow the electronic collection of patient information and healthcare details. A number of commercial hardware and software solutions are available, such as ZOLL's RescueNet ePCR [20], OPEN Inc.'s SafetyPad [21] and WebMedicPro's Field- Ready ePCR Tablet [22].

Each EMS system offers several emergency medical services (Table 1). eEKAB is a modern incident dispatching information system which integrates "On-time Incident Reporting", "On-time Arrival at the incident" and "Transfer to the Health Center" health services. eEKAB can be seen as a combination of E-911, CAD and MDTS. Table 1 makes clear that eEKAB provides significant evolution and originality in relation to existing systems, especially in the framework that is proposed to be applied in Greece.

Table 1.

Services offered by EMS systems

\begin{tabular}{|c|c|c|c|c|c|c|}
\hline $\begin{array}{l}\text { EMS systems/ } \\
\text { services }\end{array}$ & $\begin{array}{c}\text { Timely } \\
\text { incident } \\
\text { perception }\end{array}$ & $\begin{array}{l}\text { On-time } \\
\text { incident } \\
\text { reporting }\end{array}$ & $\begin{array}{l}\text { On-time } \\
\text { arrival at } \\
\text { incident }\end{array}$ & $\begin{array}{l}\text { On- } \\
\text { site } \\
\text { care }\end{array}$ & $\begin{array}{l}\text { Medical care } \\
\text { during } \\
\text { transportation }\end{array}$ & $\begin{array}{l}\text { Transfer to } \\
\text { the health } \\
\text { center }\end{array}$ \\
\hline \multirow[t]{2}{*}{ E-911 } & No & Yes & No & No & No & No \\
\hline & No & No & Yes & No & No & No \\
\hline GIS & No & No & Yes & No & No & No \\
\hline MDTs & No & No & Yes & No & No & Yes \\
\hline TrackerAssist & Yes & Yes & No & No & No & No \\
\hline ManDown & Yes & Yes & No & No & No & No \\
\hline MPDS & No & No & Yes & No & No & No \\
\hline STREMS & No & No & No & Yes & Yes & No \\
\hline ePCR & Yes & Yes & No & No & No & No \\
\hline eEKAB & No & Yes & Yes & No & No & Yes \\
\hline
\end{tabular}




\section{The eEKAB information system}

The eEKAB's development follows the three phases of the agile Scrum process which are pregame, development and postgame. Pregame includes both planning and architecture level design. The architecture of the system is based on the components that are available in the product backlog. System requirements arising from customer communication, sales or marketing are collected and prioritized, creating the product backlog list. The Scrum team implements only the features that have been previously pointed out in the backlog list. In the development phase, the main goal is to control the various unexpected variables that exist in the software development process. Such parameters are the available human resources, the requirements, the time and the development tools for implementation the system. The implementation time of the project is organized in several sprints, making the phase quite flexible. Each sprint lasts from one week to one month. In the postgame phase, the appropriate actions, that must be done effectively to deliver the project on time, are taken, including the proper integration, testing and documentation of the project. This phase takes place when the project is ready for release [23].

\subsection{Application requirements and design}

The general necessary requirements of an EMS are separated as functional and nonfunctional as listed, in a nonexhaustive way, in the following link: https://bit.ly/ 3tQOj1g. eEKAB was developed to meet most of these requirements. As mentioned before, it was designed to help the coordination and cooperation between the EKAB departments and more specifically the ambulance crew and the doctors. The goal of its design was to optimize the emergency care services by automating procedures and reducing the time of prehospital care procedures. For the application design, the client-server architecture was adapted to the mobile environment of the prehospital procedure [24]. eEKAB consists of a web server, connected to a database and a multitude of mobile clients who connect to the server and interact with the database. eEKAB consists of two separate modules, one designed to run on the web server and the other designed to run on the mobile clients. The application server is handled by the controllers while the mobile application is handled by the crew of the ambulances and the physicians who play the role of mobile clients. The mobile clients are mobile phones that the doctors and the ambulance crew must connect to the web server and interact with the database. Both applications use two agents, one on the server side and one on the client side so that the communication follows the scheme clientagent-agent-server and vice versa. These agents handle the communication between the server and the clients asynchronously. Thus, the control center is not delayed by the required connection between client and server as it is asynchronous. In addition, it is possible to adopt a publish-subscribe model for the services used. The scenario followed by eEKAB is described in Figure 1.

When an emergency call reaches the eEKAB call center, the person at the help desk starts recording the patient's details. Then, he selects the nearest available doctor and ambulance from the list of clients. The ambulance crew and the doctors receive a notification on their mobile devices that an incident is in progress. When they open the notification, the incident location and instructions on how to arrive are automatically displayed on their mobile screen. In parallel, with the help of agents, the database is updated that this ambulance/doctor took over the incident. Finally, when the ambulance/doctor successfully offers its services in the incident, he closes the notification and informs the corresponding database.

\subsection{Implementation details}

The mobile applications were developed using the Google Android operating system. This system provides seamless support for network communication, through socket
Mobile
computing for
emergencies

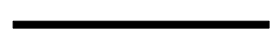




\section{$\mathrm{ACI}$}

Figure 1.

The architecture of eEKAB
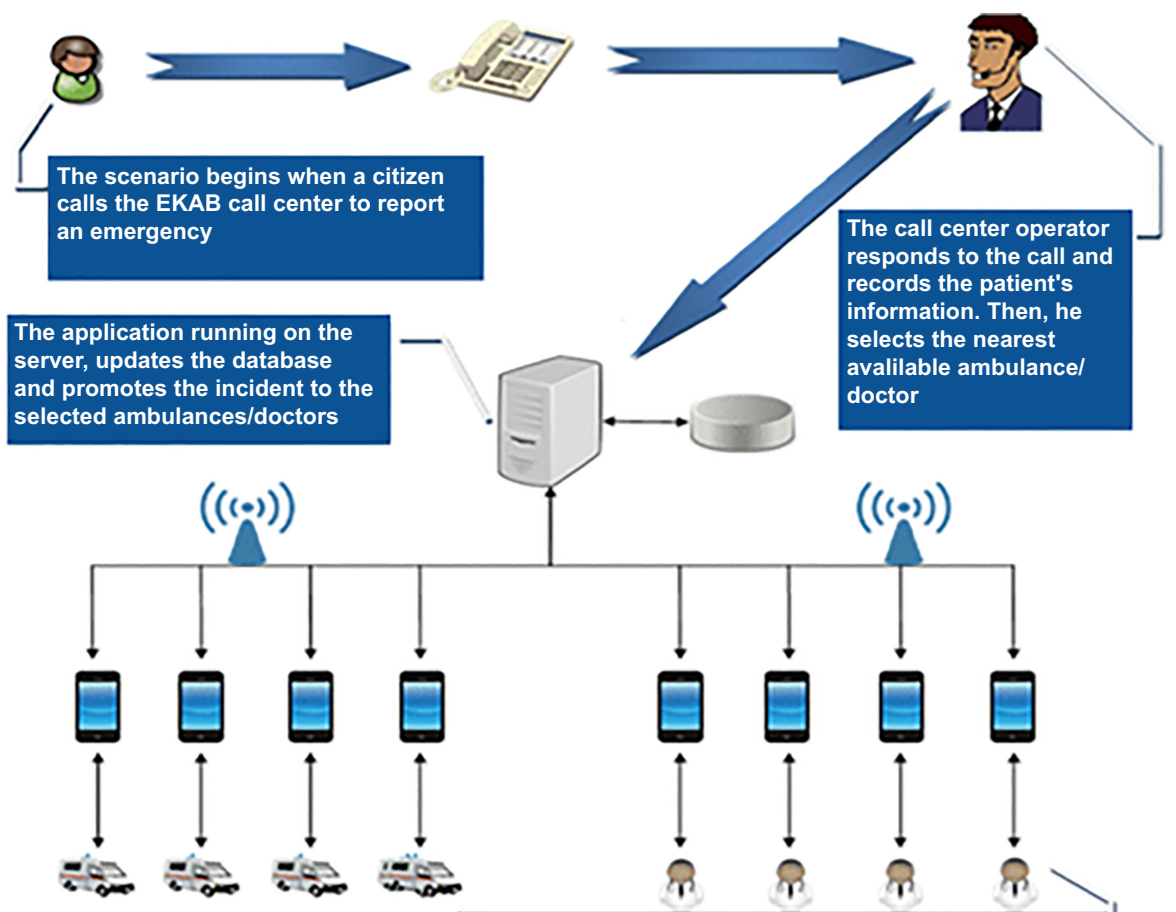

$(((\circ)))$

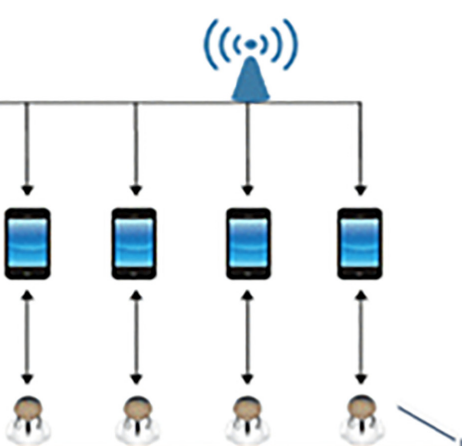

The application that runs on mobile devices can operate

on two situations. One is the standby, in which it waits to

bet notified for an incident while updating the database

periodically for the client's location. The other, in which

it has received the notification for an incident and

provides instructions to the client for rapid arrival in the

scene

programming and WiFi and allows its integration with maps using the Google Map API and a GPS sensor. eEKAB leverages on these and other built-in sensors to update the relevant databases.

The Google Map API is used to implement the process of presenting a map to clients showing their location and the shortest route to their destination. Through this API, the control center can visualize location maps of the ambulances, the doctors and the incident. Thanks to the Google web service, the distances and the estimated time of an ambulance or a doctor can be calculated, so that the closest to the incident people can be identified.

The application server for the operations center was implemented using PHP (Hypertext Preprocessor). The application launch triggers another program that plays the agent role and takes over the part of communicating with the client through sockets. The REST architectural style was used to distribute the communication overhead between the operations center and the ambulance application. Each REST API establishes a loosely coupled communication between the client and the server via HTTP and enables the servers to cache the response. As a result, they improve the performance of the application. Multiple types of new clients can be also introduced without considering the backend implementation. The available clients communicate with the backend endpoints as shown in Figure 2. 
jQuery, a JavaScript library for easier HTML development, was used for checking the events (e.g. the actions that follow when a button is pressed), for checking all forms for incorrect insertions and for presenting the original application records and dialog boxes as well as the forms for importing/modifying ambulances and doctors.

In addition, Ajax helped us to perform some operations asynchronously. Specifically, Ajax is used in the field of the incident address to display a list of possible addresses (which are valid Google map addresses), depending on the typed address to ensure its validity. Moreover, the list of available ambulances and doctors is provided asynchronously when requesting the form with the incident details.

\subsection{Web operations}

Hereafter, some operations that contribute to the user experience are briefly presented. By selecting in the mobile application, the function, named "Emergencies", the recording of the medical incidents is performed. To the left of the application home page, the incidence entry form is depicted, while to the right, a map (naturally derived from Google Maps) showing the incident, the available doctors and the available ambulances. As soon as the user enters the correct values in all fields and presses the "Submit" button, the incident is automatically inserted into the database and a new area appears at the bottom of this page, called "Doctors and Vehicle Search". The map demonstrates all the available doctors and all the currently available ambulances. The incident appears in red and with the letter I (Incident), the doctors in blue and with the letter D (Doctor) and the ambulances in green and with the letter $\mathrm{A}$ (Ambulance). At https://bit.ly/3uDnGxa, a demonstration part of the "Doctors and Ambulances Search" area after reporting the incident and the nearest route to reach it is depicted. In companion of that, lists for ambulances and for doctors are available to the staff so that they are aware of the details of all the involved entities.

\subsection{Mobile operations}

The user authentication on the mobile application is achieved by filling the phone number and the given secret code for the mobile phone owner. The client receives a popup message to confirm whether the authentication was successful. Once the login form is completed, a warning message that automatically closes in 20 seconds is displaced indicating the username and informing him about four things:

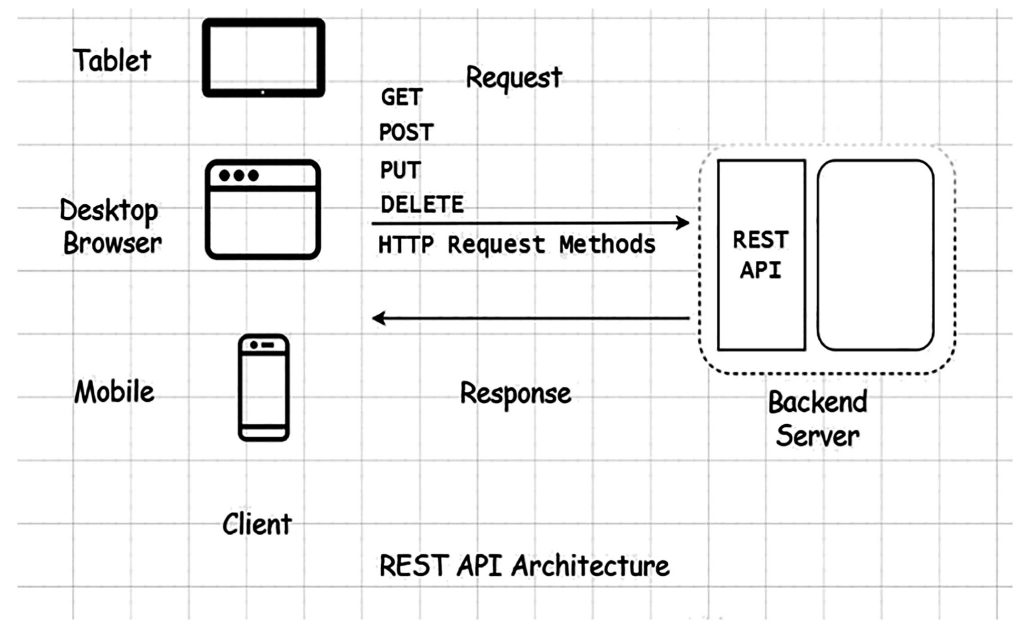

Figure 2.

The architecture of the REST API 
(1) The mobile was connected to the central server application.

(2) The application will periodically send the location of the mobile to the central eEKAB application, informing the central server database.

(3) The application is now running in the background, waiting to receive an incident.

(4) If an incident is received, then, a notification is displayed on the mobile phone.

In case an incident is sent to the ambulance, a new notification on the respective mobile phone informs the crew that a new incident has arrived. As soon as the alert is opened, a Google map shows the current position of the ambulance (blue dot) and the route to the incident (Figure 3).

\section{Evaluation}

\subsection{Criteria-driven evaluation approach}

The criteria-driven approach that uses evaluation criteria was used in this work [25, 26]. The focus of this approach is on setting specific properties that are important for the evaluation of the information systems. The evaluation is based on defined criteria without user intervention as there were no users available to contribute to the evaluation. The criteria are divided into categories with specific category and criteria weights. The following formula is used [25]:

$$
Q=\sum_{j=1}^{n} w_{j} \sum_{i=1}^{k j} s_{j i} w_{j i}
$$

where $w_{j}$ is the category weight $j, s_{j i}$ is the value of criterion $i$ of category $j, w_{j i}$ is the weight of $i$ of category $j, n$ is the number of categories and $k_{j}$ is the number of evaluation criteria of category $j$. $Q$ provides an appropriate assessment metric of the quality performance of EMS. It reveals to what degree the fulfillment of the set requirements is achieved. Indicative evaluation criteria with their respective weights and criteria value are presented in Table 2.

Due to space limitations, a short example is provided, which provides details of the second evaluation criterion of Table 2, namely the cost. The cost of eEKAB is derived from the web

Figure 3.

Route from the location of the cellphone (light blue dot) to the incident

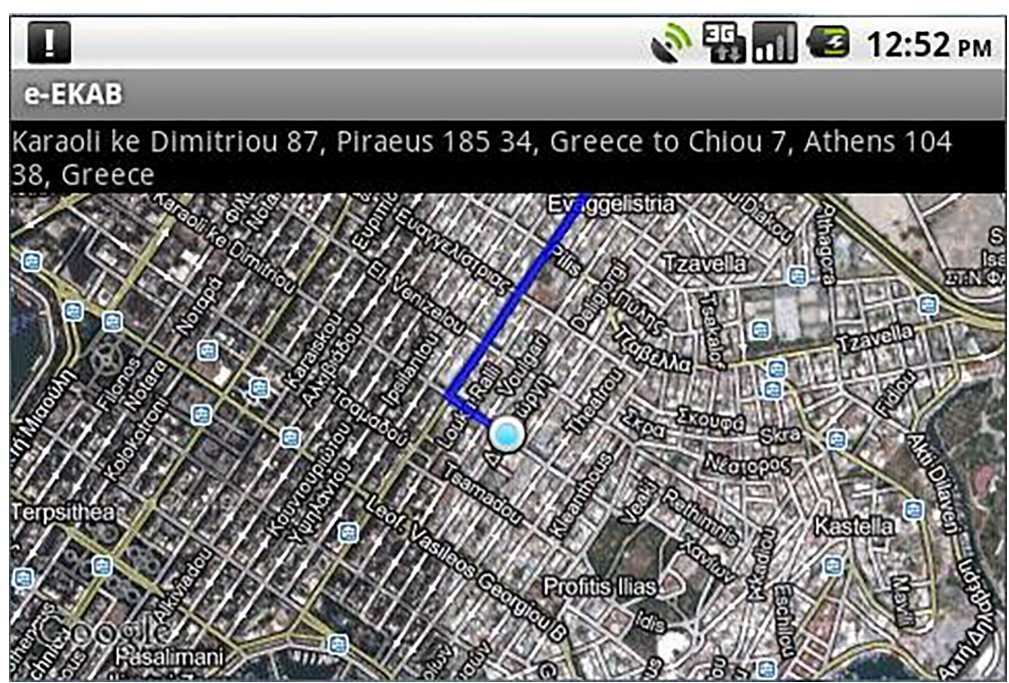




\begin{tabular}{|c|c|c|c|c|c|c|c|c|c|}
\hline \multirow[b]{2}{*}{$\begin{array}{l}\text { Evaluation } \\
\text { criteria }\end{array}$} & \multicolumn{3}{|c|}{ Weight values } & \multicolumn{5}{|c|}{ Criterion values } & \multirow{2}{*}{$\begin{array}{r}\text { Mobile } \\
\text { computing for } \\
\text { emergencies }\end{array}$} \\
\hline & $\begin{array}{c}\text { (1): } \\
\text { Important }\end{array}$ & $\begin{array}{l}\text { (2): Very } \\
\text { important }\end{array}$ & $\begin{array}{l}\text { Extremely } \\
\text { important }\end{array}$ & $\begin{array}{c}\text { not } \\
\text { acceptable }\end{array}$ & $\begin{array}{c}\text { fully } \\
\text { qualify }\end{array}$ & $\begin{array}{c}\text { (2): It } \\
\text { qualifies }\end{array}$ & $\begin{array}{l}\text { exceeds the } \\
\text { requirements }\end{array}$ & $\begin{array}{l}\text { exceeds the } \\
\text { requirements }\end{array}$ & \\
\hline $\begin{array}{l}\text { Time } \\
\text { reduction }\end{array}$ & & & $\mathrm{X}$ & - & & $\mathrm{x}$ & & & \\
\hline Cost & & & $\mathrm{X}$ & - & & & $\mathrm{X}$ & & \\
\hline $\begin{array}{l}\text { Reduction of } \\
\text { resource } \\
\text { consumption }\end{array}$ & $\mathrm{X}$ & & & - & & $\mathrm{X}$ & & & \\
\hline $\begin{array}{l}\text { Ease of } \\
\text { drawing } \\
\text { conclusions } \\
\text { from various } \\
\text { incidents }\end{array}$ & & $\mathrm{X}$ & & - & & & & $\mathrm{X}$ & \\
\hline Easy use & & $\mathrm{X}$ & & - & & $\mathrm{X}$ & & & \\
\hline $\begin{array}{l}\text { Security } \\
\text { Confirmation }\end{array}$ & & & $\mathrm{X}$ & - & $\mathrm{X}$ & & & & \\
\hline $\begin{array}{l}\text { Confirmation } \\
\text { of receiving } \\
\text { incident } \\
\text { coordinates }\end{array}$ & $\mathrm{X}$ & & & - & $\mathrm{x}$ & & & & \\
\hline Valid address & $\mathrm{X}$ & & & - & & & & $\mathrm{X}$ & \\
\hline $\begin{array}{l}\text { Form } \\
\text { checking }\end{array}$ & $\mathrm{X}$ & & & - & & & & $\mathrm{X}$ & \\
\hline $\begin{array}{l}\text { Cooperation } \\
\text { between }\end{array}$ & & $\mathrm{x}$ & & - & & & $\mathrm{X}$ & & \\
\hline $\begin{array}{l}\text { EKAB } \\
\text { departments }\end{array}$ & & & & & & & & & $\begin{array}{r}\text { Table } 2 . \\
\text { Weights and criteria }\end{array}$ \\
\hline $\begin{array}{l}\text { Use of modern } \\
\text { technologies }\end{array}$ & $\mathrm{X}$ & & & - & & & & $\mathrm{x}$ & $\begin{array}{l}\text { values of the } \\
\text { evaluation criteria }\end{array}$ \\
\hline
\end{tabular}

server cost, the cost of the android mobile devices, the cost of the professional Google Maps service and the network cost. The web server cost will range from 2,000 to 5,000 euros. We also need around 1,200 mobile android phones (based on the number of EKAB vehicles). Assuming the cost of a mobile android is 75 euros, their total cost is about $75 \times 1200=90,000$ euros. For their interconnection, a mobile VPN (virtual private network) is used, which provides the greatest possible reliability and security and costs about 88,800 euros a year. The Google Map service costs 8,000 euros per year. The prices are indicative, but the cost is approximately 100,000 euros for the original equipment plus approximately 100,000 euros per year for the provided services. These costs are by no means prohibitive for a public service such as EKAB. On this criterion, a weight value of 3 is given, as it is considered a very important part of the EMS and criterion value 3 as we consider that the cost for upgrading a very critical public service is quite low. Next, the total application effectiveness $Q$ was calculated as follows:

$$
\begin{aligned}
Q= & 3 \times(3 \times 2+3 \times 3+1 \times 2+2 \times 4)+1 \times(1 \times 4+2 \times 2+3 \times 1)+2 \times(3 \times 2 \\
& +3 \times 1+1 \times 4+1 \times 4)+1 \times(2 \times 3+1 \times 4) \\
= & 3 \times(6+9+2+8)+1 \times(4+4+3)+2 \times(6+3+4+4)+1 \times(6+4) \\
= & 3 \times 25+1 \times 11+2 \times 17+1 \times 10=75+11+34+10=130 \Leftrightarrow Q=130
\end{aligned}
$$

We observe that the system performance is 130 . That on its own is not enough to provide a sense of the performance of the information system. For this reason, its performance is 
compared with the performance of four other systems. The first system that does not fully meet the initial requirements applies the yield $Q=52$ (expressing the current EKAB system). The second system fulfills the requirements and has a yield of $Q=104$. The third slightly exceeds the requirements and gives a $Q=156$ and, finally, the fourth system substantially fulfills the requirements with a $Q=208$. We observer that eEKAB has a $Q$ value between the second system that meets the requirements and the third that slightly exceeds them. Furthermore, if we assume that the perfect system has $Q=208$ then, our system has a $62.5 \%$ efficiency on a scale of 100, which means that further system usage and processes improvements must be enforced.

On the other hand, the proposed system compared to the current system of EKAB is more efficient. Indeed, eEKAB improves the current system of prehospital medical care in computerization of incident data with the ability to analyze them and draw conclusions, in reduction of EKAB procedures time, in more efficient management of the EKAB system, in better distribution of human resources, in better geographical distribution of ambulances/ doctors after case analysis and in visualization of ambulance/doctors map and route to the incident. The high-level estimation in the performance for the eEKAB system is obvious since both the ambulance matching and the map navigation steps have been fully automated. Figure 4 depicts the differences before and after the adoption of automated EMS services toward the direction to reduce both the time and the cost.

\subsection{Survey evaluation based on functional specifications of eEKAB}

The evaluation of the functional requirements was applied through a survey, using the quantitative research method. The aim was to determine whether the users of the eEKAB identify any advantages or useful features. The research was conducted online via simulation on 100 ambulance drivers who evaluated the importance of the application when an emergency incident call was available. The ambulance drivers downloaded the application to their mobile phones, created their free account and used it in terms of providing emergency prehospital care to the patients. The ambulance drivers received a notification via the eEKAB application and observed on the map if the ambulance crew could arrive in the incident's location on time. After having used the application at least once, they had to complete a questionnaire to express their satisfaction or displeasure, regarding the application. The survey data are provided in the following link: https://bit.ly/32KDJgu.

The analysis of the research demonstrates that there were 74 drivers under 40 years old and 26 above 41 years old. We used SPSS to process and analyze the survey data. The chisquare statistic test was applied to investigate whether the effectiveness of the eEKAB application is correlated with the age difference of the ambulance drivers. The statistic test $\left(X^{2}=100, p=.00\right)$ proved that $74 \%$ of the ambulance drivers who are under 40 years old expressed their satisfaction about the essential and vital contribution of the application to the provision of emergency health care to the patients. It seems that the younger ambulance drivers tend to find the eEKAB more effective. The survey analysis is provided in the following link: https://bit.ly/2Pk7x0h.

The bivariate statistic test was used to calculate the Pearson correlation coefficient to investigate the existence of a statistically significant relationship between the effectiveness of the notification for the incident's location with the responder's perception on recommending the eEKAB application to other ambulance drivers and having a friendly user experience for accessing useful information via the mobile phone. The analysis showed that there is a perfectly positive linear relationship $(r=1, p=0.00)$ between the immediate sending of the emergency notification and the positive perception from responders on adopting the eEKAB beyond pilot mode. Also, a perfectly positive linear relationship $(r=1, p=0.00)$ emerged between the speed of sending the alert and the increased probability of recommending the 


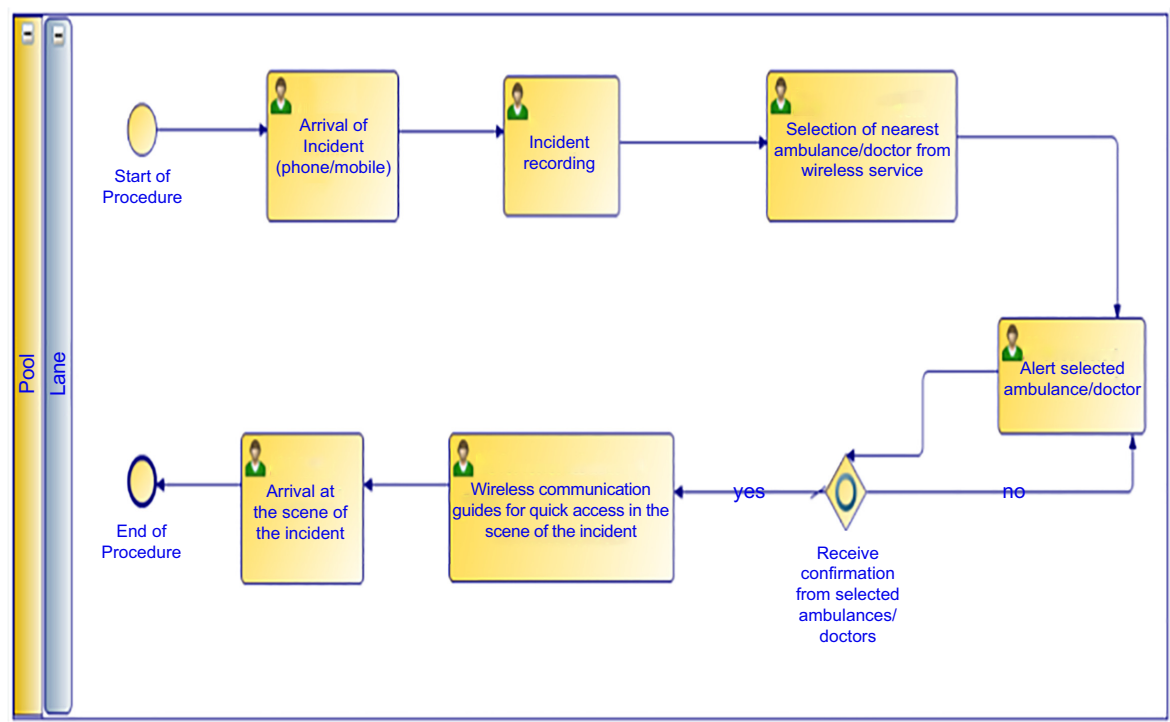

\section{Mobile computing for emergencies}

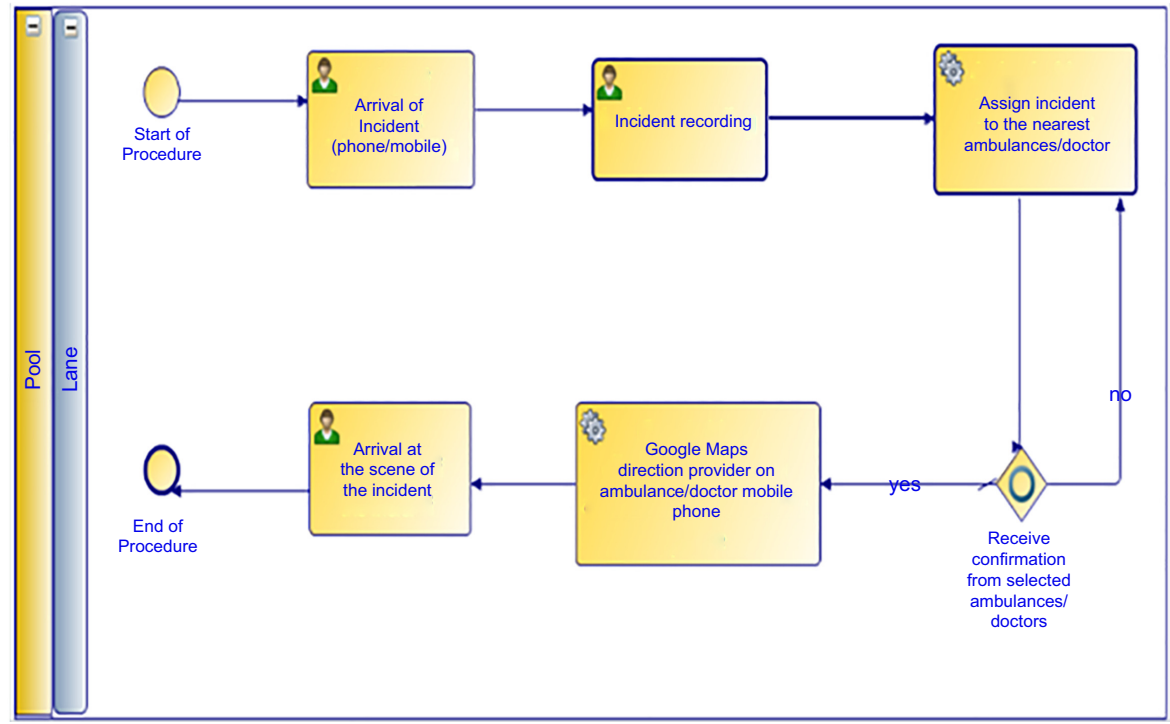

Figure 4.

EMS procedures before and after eEKAB

application to new ambulance drivers. Finally, there was a perfectly positive linear relationship $(r=1, p=0.00)$ between taking into account immediately the alert without delay and easily finding the route to quickly pick up the patient from the location indicated by the application. The results highlight the fact that receiving the notification on time significantly helps the ambulance drivers to properly transport the patients to the hospital. Thus, they consider the application efficient enough, and they want to recommend it to other colleagues and promote it beyond its pilot test phase. The Pearson metrics are provided in the following link: https://bit.ly/3dNSbKT. 


\section{Conclusions and future work}

In this paper, the basic architecture and the development of eEKAB, a system that improves the overall pre-hospital care process, were presented. eEKAB provides a computerization of the incident data with the capability of analyzing them and drawing conclusions. It reduces the total time of the EMS procedures, and it allows for an easier management of EMS, by providing a better allocation of human resources and a better geographical distribution of ambulances.

Various areas can certainly be improved. One area where the system can improve is its security. The network that will be used should be highly secure. One option is the use of a mobile VPN that will allow clients to stay connected to the EKAB network even if they switch wireless networks on their own. Additionally, there is the issue of carrying out the nonconfirmation the receipt of an incident assignment by ambulances or doctors.

The system can evolve to include better communications among the EKAB departments. Particularly, the ambulance crew as well as the doctors should be informed with more incident features such as the emergency signal so that they know whether to open the siren and the patient's name. In addition, ambulances/doctors should be able to inform the control center about the conditions they found at the incidence location and about data on the time spent on the scene. Regarding interoperability, the mobile app cooperates with the Operational Center of EKAB, while further collaboration could be achieved with other operational ambulance handling center, mainly, of the private sector. We are currently working on implementing some features to provide effective medical health services to the patient in the ambulance. This is very important as it is going to measure the health status of the patient and predict the potential health care costs and resources that are needed for the hospital health care.

\section{References}

[1] Roudsari, BS. et al. Emergency Medical Service (EMS) systems in developed and developing countries. International J Care Inju. 2007; 38(9): 1001-1013 [cited 2020 Mar 16], Available at: https://www.injuryjournal.com/article/S0020-1383(07)00167-2/abstract.

[2] Al-Shaqsi S. Models of international emergency medical service (EMS) systems, Oman Med J. 2010; 25(4): 320-323 [cited 2020 Mar 16], Available at: https://bit.ly/2TRkY7u.

[3] U.S. Dep. of Transportation. Star of life: emergency medical care symbol. 2020 [cited 2020 Nov 02], Available at: https://www.ems.gov/vgn-ext-templating/ems/sol/HS808721.pdf.

[4] Walz BJ, et al. Foundations of EMS systems. 2020 [cited 2020 Mar 16], Available at: https://bit.ly/ 38QXAva.

[5] Schooley B. et al. ITS and transportation safety: EMS system data integration to improve traffic crash emergency response and treatment - phase IV and V: ITS Institute, Center for Transportation Studies, Minessota: Univ. of Minessota; 2012.

[6] Turoff M. et al. The design of a dynamic emergency response management information system (DERMIS). J Inf. Technol Theor Appl. 2003; 5(4): 1-35.

[7] Dick WF. Anglo-American vs. Franco-German emergency medical services system. Prehosp Disaster Med. 2003; 18(1): 29-35, Discussion 35, Jan-Mar 2003.

[8] Xu B. et al. Ubiquitous data accessing method in IoT-based information system for emergency medical services, mely and ubiquitously in a cloud and mobile computing platform", IEEE Trans Indus Info. 2014; 10(2): 1578-1586.

[9] Dawson D. National emergency medical services information system (NEMSIS), J Prehospital Emerg Care. 2006; 10(3): 314-316.

[10] BIJ and NIJ. Standard functional specifications for law enforcement computer aided dispatch (CAD) systems. 2020 [cited 2020 Nov 02], Available at: shorturl.at/dJLN5. 
[11] 911 Service. 2020 [cited 2020 Mar 16], Available at: http://agilisnet.com/911-service/.

[12] Adams R. et al. Emergency medical services priority dispatch. Ann Emerg Med. 1993; 22(11): 1688-169.

[13] CAD. Emergency medical services authority; 2020 [cited 2020 Mar 16], Available at: https://bit.ly/ 33iTxGR.

[14] Pugh K. Define police computer aided dispatch system. 2020 [cited 2020 Mar 16], Available at: https://bit.ly/2TQ5xMP.

[15] ESRI. Fire, rescue, and emergency medical services. 2020 [cited 2020 Mar 16], Available at: https://bit.ly/3aZ8Kzq.

[16] Harman LJ, Shama U. Mobile data Terminals: a synthesis of transit practice. 2007 [cited 2020 Mar 16], Available at: https://bit.ly/2QktpWz.

[17] Wu X. et al. A smart real-time solution towards enhancing EMS prehospital quality. 2017 [cited 2020 Mar 17], Available at: https://bit.ly/33mRDoA.

[18] Samuels. et al. Five pillar deployment plan: a journey to deployment in EMS systems. J Bus Edu Lead. 2018 [cited 2020 Nov 02], Available at: shorturl.at/ahqX6.

[19] Wu X, Dunne R, Yu Z, Shi W. STREMS: a smart real-time solution toward enhancing EMS prehospital quality. 2017 IEEE/ACM International Conference on Connected Health: Applications, Systems and Engineering Technologies (CHASE). 2017. doi: 10.1109/chase.2017.120.

[20] ePCR. Build dynamic patient care records that tell a complete story. 2020 [cited 2020 Mar 17], Available at: https://bit.ly/2vs9Lkq.

[21] ESO. SafetyPAD. 2020 [cited 2020 Mar 17], Available at: http://www.safetypad.com/.

[22] EMS1 Academy. Medapoint conducting webinar March 2nd, 2016. Demonstrating the benefits of cloud ePCR. 2016 [cited 2020 Mar 17], Available at: https://bit.ly/2WgwfQm.

[23] Abrahamsson P, Salo O, Ronkainen J, Warsta J Agile software development methods: review and analysis. Espoo: VTT Publication 478; 2002, 107, Available at: http://www.vtt.fi/inf/pdf/ publications/2002/P478.pdf.

[24] Jing J. et al. Client-server computing in mobile environments. ACM Comput Surv. 1999; 31(2) June 1999, [cited 2020 Mar 17], Available at: https://bit.ly/3b44IWw.

[25] Al-adaileh RM. An evaluation of information systems success: a user perspective - the case of Jordan telecom group. 2009 [cited 2020 Mar 17], Available at: https://bit.ly/3a3M140.

[26] Vasilecas O. et al. Evaluation of information systems procurement: goal and task-driven approaches. ISSN 1392 - 124X Info Tech Cont. 2006; 35(3) [cited 2020 Mar 17], Available at: https://bit.ly/3d2GTjL.

\section{Further reading}

[27] Ramanayake RP, Ranasingha S, Lakmini S. Management of emergencies in general practice: role of general practitioners. J Fam Med Prim Care. 2014; 3(4): 305-308. doi: 10.4103/2249-4863.148089.

\section{Corresponding author}

Sarandis Mitropoulos can be contacted at: smitropoulos@ionio.gr

For instructions on how to order reprints of this article, please visit our website:

www.emeraldgrouppublishing.com/licensing/reprints.htm

Or contact us for further details: permissions@emeraldinsight.com 